\title{
Oxidation/absorption of arsenite in groundwater using ozono/activated carbon from coconut shell charcoal
}

\begin{abstract}
Oxidation of $\mathrm{As}(\mathrm{III})$ to $\mathrm{As}(\mathrm{V})$ with ozone was investigated in groundwater sample containing $0.5 \mathrm{mg} \mathrm{L}^{-1}$ at $\mathrm{pH} 10.0$ with ozone doses of $1.3 \mathrm{~g} \mathrm{~L}^{-1}$ during $30 \mathrm{~min}$ for the ozone reaction with more than $90 \%$ efficiency. The $\mathrm{pH}$ of the solution was an important parameter in the rate of oxidation. The absorption process was carried with two commercial activated carbon sources, one from wood and the other from coconut shell at different $\mathrm{pH}$ 's. Coconut shell charcoal showed greater efficiency for the adsorption of As (V) as compared to wood charcoal. This is because coconut shell charcoal has better adsorptive characteristics such as pore size, surface area and surface functional groups. Using $187.4 \mathrm{mg}$ of ozone for the oxidation of $0.1 \mathrm{mg}$ of $\mathrm{As}(\mathrm{III})$ the oxidation process reaches the $99 \%$ of efficacy. At $\mathrm{pH} 5.0$ with initial concentration of $0.5 \mathrm{mg} \mathrm{L}^{-1}$ of $\mathrm{As}(\mathrm{V})$ and a contact time of 240 min reaches an efficiency of $90 \%$ of arsenic removal.
\end{abstract}

Keywords: Arsenic; Oxidation; Ozone; Absorption; Activated carbon; Coconut shell; Water treatment
Volume 5 Issue 5 - 2017

\author{
Laura María Acevedo Afanado, María Rita \\ Valladares Rodríguez, Clementina Rita \\ Ramírez Cortina, Erasmo Flores Valverde, \\ Manuel Soriano-García \\ Departamento de Química de Biomacromoléculas, Instituto de \\ Química, Universidad Nacional Autónoma de México, México

\begin{abstract}
Correspondence: Soriano-García M, Departamento de Química de Biomacromoléculas, Instituto de Química, Universidad Nacional Autónoma de México, UNAM, Delegación Coyoacán, Ciudad de México 045I0, Tel 5255-5622 4569, Fax 52555616 2217, Email Soriano@unam.mx
\end{abstract}

Received: July 19, 2017 | Published: July 31, 2017

\section{Introduction}

Arsenic (As) is a ubiquitous element present in various compounds throughout the earth's crust. Contamination of the environment with arsenic from both natural and anthropogenic sources is widespread, occurs in many parts of the world and may be regarded as a global issue. It is widely distributed and mainly transported in the environment by water. Arsenic can impact human health through the ingestion of surface and ground water used for water supply. Chronic arsenic poisoning occurs in many countries, in which the arsenic concentration is up to $2 \mathrm{mg} \mathrm{L}^{-1}$. $^{1,2}$ There is several removal techniques of arsenic widely used such as ion exchange, adsorption in activated carbon from different natural sources, reverse osmosis, coagulation with conventional iron and aluminum salts such as ferric chloride and aluminum sulfate/filtration, lime precipitation, selective membrane methods, absorption onto metal oxides or hydroxides in fixedbed filters, oxidation with ozone/filtration, and various biological approaches. Each method has its advantages and disadvantages, and individual water treatment plant may choose the method that best suits their financial and managerial situations. In all above techniques follows the preoxidation that coverts $\mathrm{As}(\mathrm{III})$ to $\mathrm{As}(\mathrm{V})$, which has a higher adsorption towards many absorbents. ${ }^{3}$ The most characteristic chemical properties of ozone are its strong oxidizing and high standard redox potential according to the reaction conditions. It is strong oxidizing nature and its tendency to transfer an $\mathrm{O}$ atom with coproduction of $\mathrm{O}_{2} \cdot{ }^{4}$ In some cases, free radicals are formed from the ozone oxidation. The free radicals propagate themselves through the mechanisms of elementary steps to yield hydroxyl radicals. These hydroxyl radicals are extremely reactive with any organic and inorganic compounds. ${ }^{5,6}$ This reports presents the rates of oxidation of naturally occurring As(III) in groundwater samples in the presence of ozone. Coupling of arsenic oxidation to an absorption reaction process using carbon activate from coconut shell. The results obtained from this study should serve as bases in developing an effective methods to remove toxic As(III) from groundwater supplies.

\section{Materials and methods}

To generate ozone a continuous oxygen flux enters the ozone generator and makes the ozone under an electric discharge. Ozone flux production by the generator follows the $2350 \mathrm{E}$ method describe in the Standard Methods for the Examination of Water and Wastewater 22 nd edition. For an ozonation method to be effective, the gas must be dissolved in a $2 \%$ of potassium iodine solution during five minutes, then $10 \mathrm{~mL}$ of $2 \mathrm{~N}$ sulfuric acid is added and the solution is valorized with $0.1 \mathrm{~N}$ of sodium thiosulfate. The ozone concentration can be estimated by the amount of sodium thiosulfate used. The reaction produced potassium iodide with an iodine release. As(III) and $\mathrm{As}(\mathrm{v})$ were separated by using Dowex resin (Chloride form) its activation was performed by using acetic acid. The resin allowed As(III) to pass through it, but completely retained the $\mathrm{As}(\mathrm{V})$. The effects of ozone application rate, $\mathrm{pH}$ of the reaction $(5,7$ and 10$)$, oxidation of As(III) to As(v) performance by using an atomic absorption spectrophotometer GBC 932 A.A instrument equipped with the generation of hydrides. Two types of granulated activated carbon were provided by the CLARIMEX Company. (1) Activated carbon Type VG 6x20 and (2) Activated carbon from coconut shell Type CG $100012 \times 40$. Their activation was carried with phosphoric acid and hot steam, respectively. Before using both activated carbon samples their moisture content, apparent density, $\mathrm{pH}$, determination of total ash, determination of iodine, rating thiosulfate solution and assessment of the iodine solution were determined. The surface area and pore size were determined using the adsorption isothermal of S. Brunauer, P. Emmett y E. Teller (BET) with Micromeritics triStar III equipment. This analysis uses gaseous $\mathrm{N}_{2}$ as an absorbent at $77^{\circ} \mathrm{K}, \mathrm{N}_{2}$ covers the entire range of porosity and weakly interacts weakly with the solid. A stock solution of $\mathrm{As}(\mathrm{III})$ and $\mathrm{As}(\mathrm{V})$ were prepared from arsenic trioxide, $\mathrm{As} 2 \mathrm{O} 3$ and sodium arseniate, $\mathrm{Na}_{3} \mathrm{AsO}_{4}$ at $10 \mathrm{mg}$ $\mathrm{L}^{-1}$ concentration. All chemicals were available commercially and the solvents were purified as conventional methods before use. ${ }^{7}$ Aqueous solutions required for the analysis were prepared by using water that was purified by a Millipore water purification system. 


\section{Results}

In this work it became clear that the use of ozone in the treatment of groundwater is very effective due to its high oxidizing capacity to convert $\mathrm{As}(\mathrm{III})$ to $\mathrm{As}(\mathrm{V})$. Arsenic is one of the most toxic elements found in water. Both of them are the major sources of arsenic poisoning. It is known that $\mathrm{As}(\mathrm{V})$ can be more easily removed from water by absorptive methods than As(III). The optimum $\mathrm{pH}$ for the oxidation of As(III) to As(V) in the presence of ozone was 10 because of the formation of free hydroxyl groups, which react quickly with the As(III) with efficiencies greater than $90 \%$.

\section{Discussion}

The process of oxidation of As(III) using ozone showed high efficiency for the four concentrations studied. The reported values of oxidation percentages are greater than $90 \%$ for ozone concentrations of 0.5 and $1.0 \mathrm{mg} \mathrm{L}^{-1}$. The results of the tests carried out show that coconut shell charcoal showed greater efficiency for the adsorption of $\mathrm{As}(\mathrm{V})$ as compared to wood charcoal. This is because coconut shell charcoal has better adsorptive characteristics such as pore size, surface area and surface functional groups. It was observed that the $\mathrm{pH}$ value of the solution is a significant variable for the adsorption of $\mathrm{As}(\mathrm{V})$, better yields over $90 \%$ are obtained at $\mathrm{pH}$. The study of adsorption isotherms for As(V) shows a Langmuir, type I model with a filling of monolayer of As (V) on the coal surface, with a capacity of 9.75 and $6.08 \mu \mathrm{g}$ As/g of carbon adsorption for a concentration of $0.5 \mathrm{mg} \mathrm{L}^{-1}$ of $\mathrm{As}(\mathrm{V})$.

\section{Conclusion}

Oxidation of As(III) with ozone and absorption of As(V) using coconut shell activated carbon combined process allows to transform $\mathrm{As}(\mathrm{III})$ to $\mathrm{As}(\mathrm{V})$ and facilitates their elimination of this toxic element through the application of optimum conditions such as $\mathrm{pH}$, ozone dose and time of reaction and contact efficiency with the absorbent producing an efficiency greater than $90 \%$.

\section{Acknowledgements}

This work has been carried during my sabbatical leave (M. Soriano-García) at the área de Química, Departamento de Ciencias Básicas, División de Ciencias Básicas e Ingenieria de la Universidad Autónoma Metropolitana-Unidad Azcapotzalco, México. This work was supported by the Cátedra "Leopoldo Río de la Loza Guillén" del Departamento de Ciencias Básicas. All the authors contributed to the biochemical studies and final editing of the manuscript.

\section{Conflicts of Interest}

Do not exists any financial or conflict of interest.

\section{References}

1. Zaw M, Emett MT. Arsenic removal from water using advanced oxidation processes. Toxico Lett. 2002;133(1):113-118.

2. Khuntia S, Majumder SK, Ghosh P. Oxidation of As(III) to As(V) using ozone microbubbles. Chemosphere. 2014;97(1):120-112.

3. Kinniburgh DG, Smedley PL. Arsenic contamination of groundwater in Bangladesh. Keyworth, UK. British Geological Survey; 2000.

4. Greenwood NN, Earnshaw A. Chemistry of the Elements. 2nd edn. UK. University of Leeds; 1997.

5. Khuntia S, Kumar SM, Ghosh P. Removal of Ammonia from water by ozone microbubbles. Ind Eng Chem Res. 2013;52(1):318-326.

6. Khuntia S, Majumder SK, Ghosh P. Microbubble-aided water and wastewater purification: a review. Rev Chem Eng. 2012;28(4-6):191192

7. Armarego WLF, Perrin DD. Purification of Laboratory Chemicals. 6th edn. Butterworth Heinemann: Oxford. 2009:138-159. 